\title{
Recalcitrant granuloma faciale with 14-year follow-up
}

\section{Keiko Shiba, Reine Moriuchi, Yusuke Morita, Yohei Hamade, Toshinari Miyauchi, Kazuhiro Kikuchi, Kikuo Tsuchiya, Satoko Shimizu}

\author{
Department of Dermatology, Sapporo City General Hospital, North 11, West 13, Chuo-ku, Sapporo 060-8604, Japan
}

Corresponding author: Reine Moriuchi, M.D., Ph.D., E-mail: parallelridge@yahoo.co.jp

\begin{abstract}
Granuloma faciale (GF) is an uncommon inflammatory dermatosis that is characterized by one or several asymptomatic brown red nodules or plaques usually occurring on the face. GF is known to be extremely resistant to treatment. Various treatments have been attempted, including topical or intralesional or systemic corticosteroids, dapsone, antimalarials, colchicine, topical tacrolimus, and topical psoralen; however, none of these have been found to be reliably efficacious. We tried numerous combinations and rotations of therapeutic modalities for GF over a long time. We described a case of GF in which the eruptions were carefully observed over the course of 14 years before finally resolving. Our experience suggests that continuous and careful follow-up, and trials of combinations and rotations of therapeutic modalities are essential for treating GF.
\end{abstract}

Key words: GF; Granuloma faciale; PSL; Prednisolone

\section{INTRODUCTION}

Granuloma faciale $(\mathrm{GF})$ is an uncommon inflammatory dermatosis that is characterized by one or several asymptomatic brown red nodules or plaques on the face and polymorphous dense dermal infiltrates with vascular damage [1,2]. GF is known to be extremely resistant to treatment, although some cases may resolve spontaneously. Various treatments have been attempted, including topical or intralesional or systemic corticosteroids, dapsone, antimalarials, colchicine, topical tacrolimus, topical psoralen in combination with ultraviolet A (PUVA), and argon and $\mathrm{CO}_{2}$ laser and surgical procedures [2-4]; however, none of these have been found to be reliably efficacious. Although GF is also known to take a long time to heal, few studies have reported the chronology of GF. The longest observation period of the $\mathrm{GF}$ cases reported in the literature was no more than 8 years [5]. Here we describe a case of GF in which the eruptions were carefully observed over the course of 14 years before finally resolving.

\section{CASE REPORT}

A 55-year-old woman presented with a 5-year history of erythematous plaques on the face in 2001. Physical examination revealed three infiltrated brownish plaques of up to $3 \mathrm{~cm}$ in diameter, one on the forehead and two on the left cheek (Fig. la). The laboratory results were normal. A biopsy specimen from a plaque on the cheek revealed dense mixed inflammatory perivascular infiltrates (Fig. 1b). The infiltrating cells consisted of eosinophils, neutrophils and plasma cells in the dermis. There was nuclear dust around the postcapillary vessels, and extravasation of erythrocytes were presented. Fibrinoid necrosis of the vessels was absent (Fig. lc). The epidermis was unaffected and was separated from the affected dermis by a 'grenz zone' of normal dermal collagen. Direct immunofluorescence demonstrated the presence of C3 deposits around small dermal blood vessels (not shown). Based on the clinical findings and histological examinations, she was diagnosed with GF. Oral dapsone (50 mg/day) was administered as the initial therapy, followed by the additional local injection of triamcinolone acetonide. As this combination therapy showed insufficient effect, an alternative combination therapy of oral prednisolone (PSL) (20 mg/day), dapsone (50 mg/day) and topical tacrolimus was introduced. Eight months after the initiation of this treatment, the lesions became moderately flat.

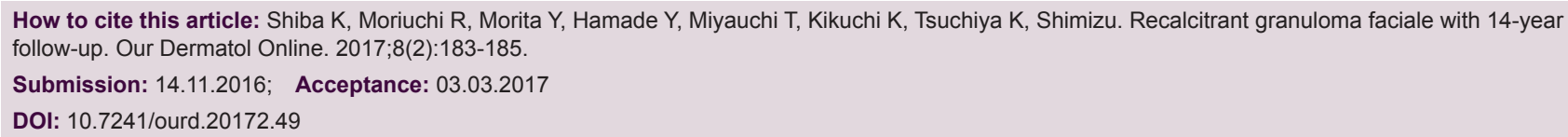


The second biopsy specimen taken at this point revealed sparse inflammatory infiltrates and mild fibrosis in the dermis (Figs. 2a and b). The PSL was gradually tapered, and the oral dapsone and topical tacrolimus were also discontinued. After we stopped administering the medication, the lesion relapsed and protruded gradually over the course of 6 months. $\mathrm{CO}_{2}$ laser monotherapy was tried four times, to no effect. From 2004 to 2008, local injection of triamcinolone acetonide (every one or two months) was reintroduced. Although this agent showed poor efficacy in 2001, it showed favorable results on this occasion. After the reintroduction of this treatment, the lesions showed remarkable improvement, leaving slight telangiectasia. The remission persisted for five years without treatment. In 2013, an additional plaque developed

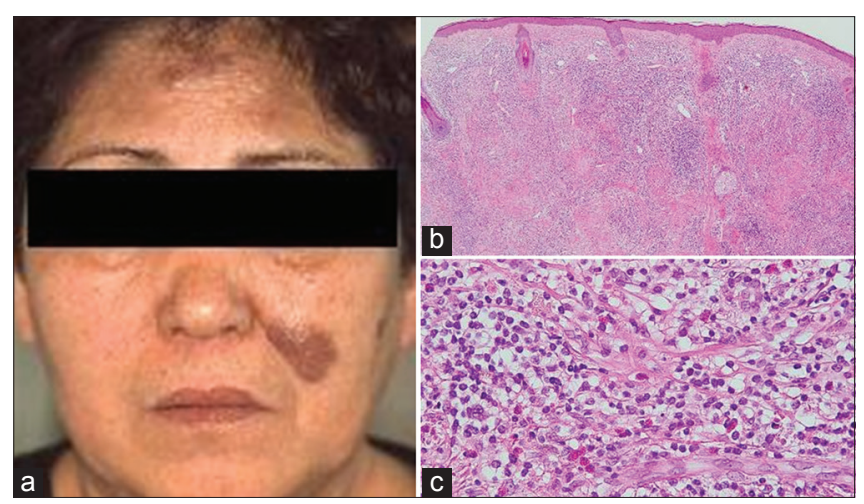

Figure 1: (a) Brownish plaques up to $3 \mathrm{~cm}$ in diameter on the forehead and the left cheek, seen in 2001. (b) A biopsy specimen from the cheek lesion reveals dense mixed inflammatory perivascular infiltrates, which are separated from the epidermis and pilosebaceous appendages by a grenz zone (H\&E stain; original magnification x 40). (c) The infiltrating cells consist mainly of lymphocytes, eosinophils, neutrophils and plasma cells. Nuclear dust and extravasation of erythrocytes are also found (H\&E stain; original magnification $x 400$ ).

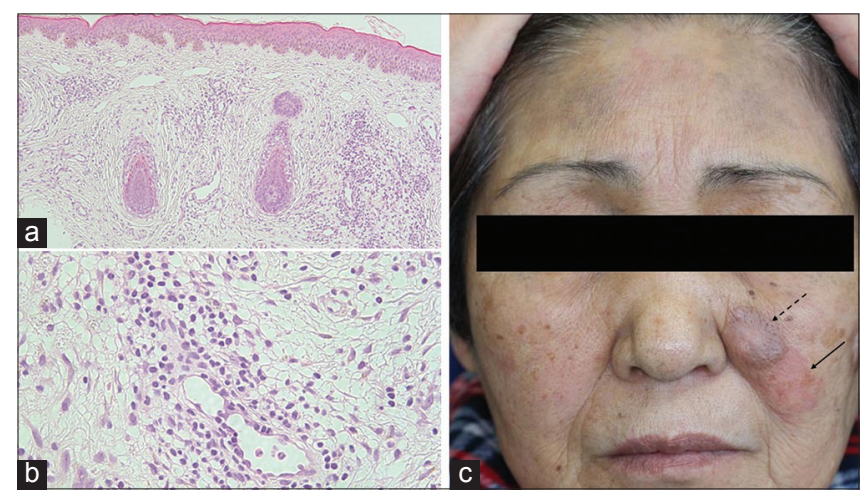

Figure 2: ( $a$ and $b)$ The second biopsy specimen reveals sparse inflammatory infiltrates and mild fibrosis in the dermis (H\&E stain; original magnification x40 (a), x 400 (b). (c) In 2013, an additional plaque (dotted arrow) develops on the upper side of the existing lesion (solid arrow). After the initiation of the cryotherapy, the existing left cheek lesions of GF markedly improves, leaving slight peripheral scarring. on the upper side of the existing left cheek lesion. We introduced the combined therapy of topical tacrolimus and triamcinolone acetonide local injection. Although both agents had previously shown efficacy, this combination therapy showed no effect. We abandoned this treatment and introduced cryotherapy using liquid nitrogen in 2014. Four months after the initiation of cryotherapy, the lesions improved markedly, leaving slight peripheral scarring (Fig. 2c). The patient is cosmetically satisfied with the results, as makeup can cover the lesion. No exacerbation has been observed for ten months without treatment.

\section{DISCUSSION}

GF is a benign condition with serious cosmetic implications. Treatment is challenging, as GF is usually resistant to various modalities [1]. Diagnosis of GF is confirmed by its characteristic clinical appearance and histologic evaluation of the lesion. The most frequent histopathological features of GF are the presence of a grenz zone and mixed inflammatory infiltrates of neutrophils, eosinophils, lymphocytes and plasma cells. Evidence of vasculitis is often present. Direct immunofluorescence may demonstrate the presence of $\operatorname{IgG}, \operatorname{IgM}, \operatorname{IgA}$ and $\mathrm{C} 3$ in the basement membrane zone and around the walls of blood vessels $[1,5]$. This disease is often characterized by chronicity, recurrence, and the onset of new lesions. Previously, 13 cases of GF treated with combination therapies were reported, such as parallel usage of cryotherapy with intralesional corticosteroid, intralesional corticosteroid with topical tacrolimus, and intralesional corticosteroid with 5-FU injection [6-10]. All cases achieved remission by these combination therapies. We tried several monotherapies and combination therapies: Oral dapsone, oral dapsone with local injection of triamcinolone acetonide, oral PSL with oral dapsone and topical tacrolimus, $\mathrm{CO}_{2}$ laser, topical tacrolimus with local injection of triamcinolone acetonide, and cryotherapy. The efficacy of these treatments varied widely over time, and sometimes it confused the therapeutic planning.

\section{CONCLUSION}

To our knowledge, this report describes the longest treatment and follow-up of recalcitrant GF ever described. The present case saw repeated exacerbation and improvement over a long time. During the disease course, we frequently faced difficulty because of the recurrence-prone nature of GF and the unreliable 
effects of the therapeutic modalities. Our experience suggests that continuous and careful follow-up, and trials of combinations and rotations of therapeutic modalities are essential for treating GF.

\section{REFERENCES}

1. Ortonne N, Wechsler J, Bagot M, Grosshans E, Cribier B. Granuloma faciale: A clinicopathologic study of 66 patients. J Am Acad Dermatol. 2005;53:1002-9.

2. Ludwig E, Allam JP, Bieber T, Novak N. New treatment modalities for granuloma faciale. Br J Dermatol. 2003;149:634-7.

3. Welsh JH, Schroeder TL, Levy ML. Granuloma faciale in a child successfully treated with the pulsed dye laser. J Am Acad Dermatol. 1999;41:351-3.

4. Verma R, Das AL, Vaishampayan SS, Vaidya S. Keloidal granuloma faciale with extrafacial lesions. Indian J Dermatol Venereol Leprol. 2005;71:345-7.

5. Marcoval J, Moreno A, Peyr J. Granuloma faciale: A clinicopathological study of 11 cases. J Am Acad Dermatol. 2004;51:269-73.
6. Requena C, Castejon P, Sanmartin O, Botella-Estrada R, Nagore E, Serra-Guillén C, et al. Rhinophyma-like granuloma faciale. J Eur Acad Dermatol Venereol. 2006;20:881-2.

7. Nasiri S, Rahimi H, Farnaghi A, Asadi-Kani Z. Granuloma faciale with disseminated extra facial lesions. Dermatol Online J. 2010;16:5.

8. Dowlati B, Firooz A, Dowlati Y. Granuloma faciale: Successful treatment of nine cases with a combination of cryotherapy and intralesional corticosteroid injection. Int J Dermatol. 1997;36:548-51.

9. Norris DL, Apikian M, Goodman GJ. Treatment of Laser Resistant Granuloma Faciale with Intralesional Triamcinolone acetonide and 5-Fluorouracil Combination Therapy. J Cutan Aesthet Surg. 2015;8:111-3.

10. Thiyanaratnam J, Doherty SD, Krishnan B, Hsu S. Granuloma faciale: Case report and review. Dermatol Online J. 2009;15:3.

Copyright by Keiko Shiba, et al. This is an open access article distributed under the terms of the Creative Commons Attribution License, which permits unrestricted use, distribution, and reproduction in any medium, provided the original author and source are credited.

Source of Support: Nil, Conflict of Interest: None declared. 